\title{
Biocatalytic Growth of Au Nanoparticles: From Mechanistic Aspects to Biosensors Design
}

\author{
Maya Zayats", Ronan Baron", Inna Popov", and Itamar Willner ${ }^{*}+$ \\ * Corresponding author. Email: willnea@vms.huji.ac.il ; Tel.: 972-2-6585272; Fax: 972-2-6527715. \\ ${ }^{\dagger}$ Institute of Chemistry, The Hebrew University of Jerusalem. \\ \$ The Unit for Nanoscopic Characterization, The Hebrew University of Jerusalem.

\section{Experimental Section}

Au-NPs $(12 \pm 1 \mathrm{~nm})$ stabilized with citrate were prepared according to the literature ${ }^{1}$. The concentration of the Au-NPs solutions was determined by two independent methods: (i) By the application of the particle dimensions determined by TEM and knowing the total numbers of gold ions that generate the NPs (with the assumption that all ions are reduced). (ii) By knowing the particles size and knowing the appropriate extinction coefficient ${ }^{2}$. Both methods gave similar values. The Au-NPs solution was stable for at least 1 month after preparation.

Growth solutions consisted of $2 \times 10^{-4} \mathrm{M} \mathrm{HAuCl}_{4}$ in $0.01 \mathrm{M}$ phosphate buffer, $\mathrm{pH}=7.2,2 \times 10^{-3} \mathrm{M}$ cetyltrimethylamonium chloride (CTAC) and either different concentrations of $\mathrm{H}_{2} \mathrm{O}_{2}$ or $\beta-\mathrm{D}(+)$ glucose with $47 \mu \mathrm{g} \cdot \mathrm{ml}^{-1}$ glucose oxidase (GOx). For the catalytic growth of the Au-NPs in solution, $3 \times 10^{-10} \mathrm{M}$ Au-NP seeds $(12 \pm 1 \mathrm{~nm})$ were added to the growth solution. The experiments were performed at ambient temperature $\left(22 \pm 2^{\circ} \mathrm{C}\right)$, unless stated otherwise stated.

Glass slides were functionalized with 3-aminopropyltriethoxysilane as described previously ${ }^{3}$, and modified accordingly ${ }^{3}$ with the citrate-stabilized Au-NPs $(12 \pm 1 \mathrm{~nm})$. The gold nanoparticles modified glass slide was then soaked in the above-described growth solution. The absorbance features of the resulting modified slides were recorded in water. 


\section{References}

(1) Grabar, K. C.; Freeman, R. G.; Hommer, M. B.; Natan, M. J. Anal. Chem. 1995, 67, 735.

(2) Link, S.; El-Sayed, M. A. J. Phys. Chem. B 2004, 43, 4519.

(3) Doron, A.; Katz, E.; Willner, I. Langmuir 1995, 11, 1313. 


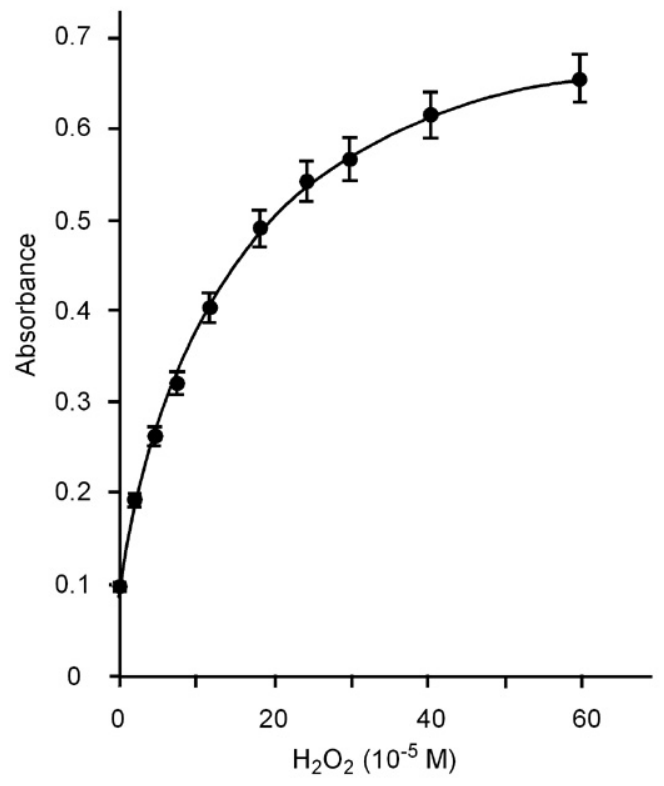

Figure 1S. Calibration curve corresponding to the absorbance at $\lambda=529 \mathrm{~nm}$ of the enhanced Au-NPs solution at variable concentrations of $\mathrm{H}_{2} \mathrm{O}_{2}$. (Experimental conditions as in Figure 1).

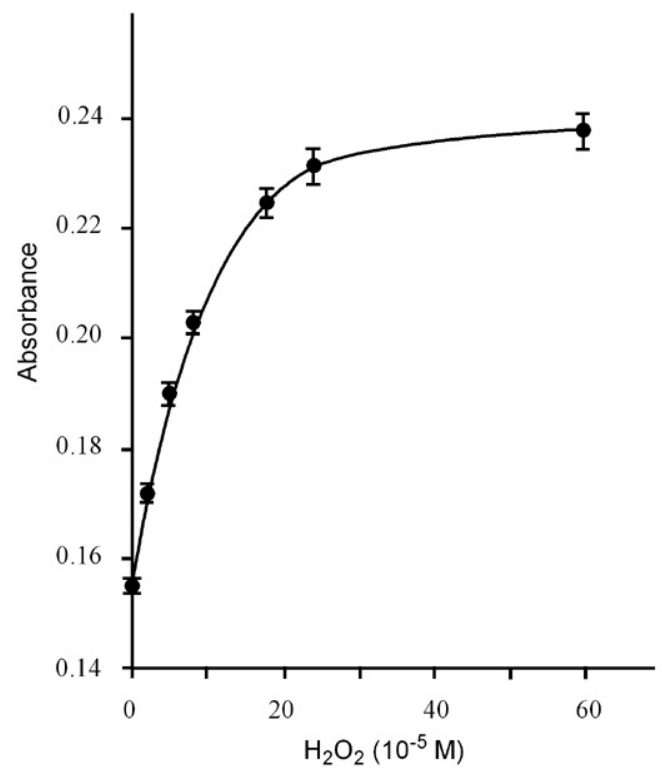

Figure 2S. Calibration curve corresponding to the absorbance changes (at $\lambda=535 \mathrm{~nm}$ ) of the Au-NPfunctionalized glass supports upon enlargement in the presence of different concentrations of $\mathrm{H}_{2} \mathrm{O}_{2}$. (Experimental conditions as in Figure 6). 

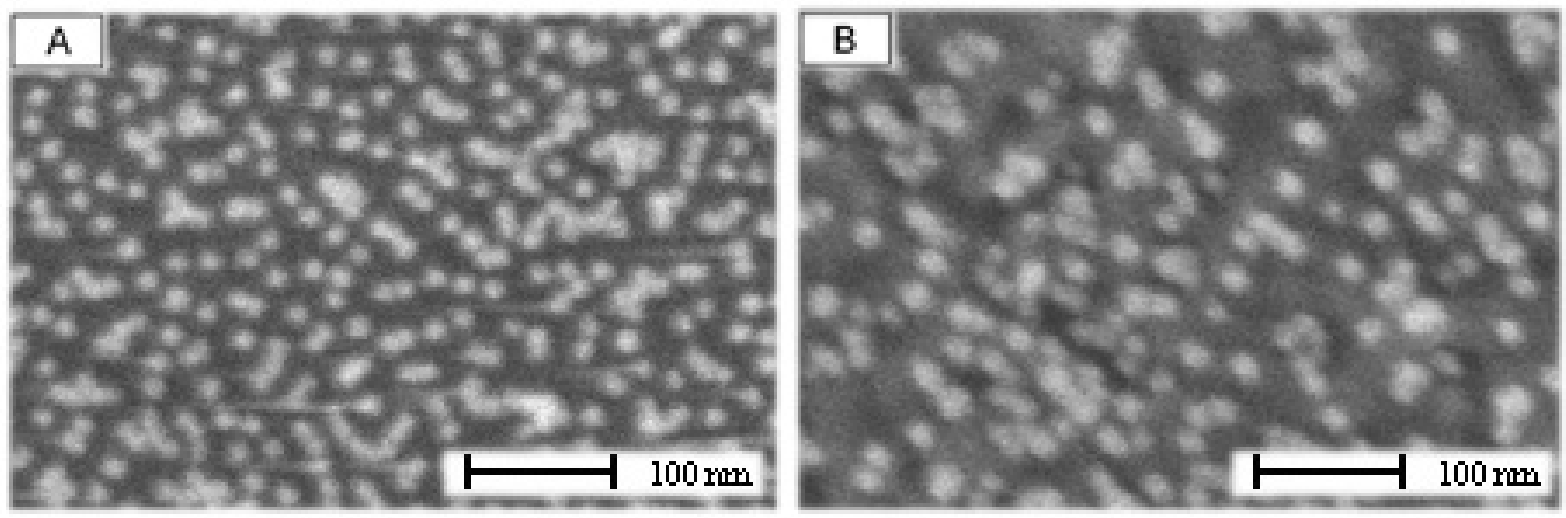

Figure 3S. HR-SEM images of Au-NP-functionalized ITO glass slides: A) after preparation B) after 10 min of reaction with $\mathrm{HAuCl}_{4}, 2 \times 10^{-4} \mathrm{M}$, in $0.01 \mathrm{M}$ phosphate buffer and CTAC, $2 \times 10^{-3} \mathrm{M}$, and $\mathrm{H}_{2} \mathrm{O}_{2}$, $1.8 \times 10^{-4} \mathrm{M}$

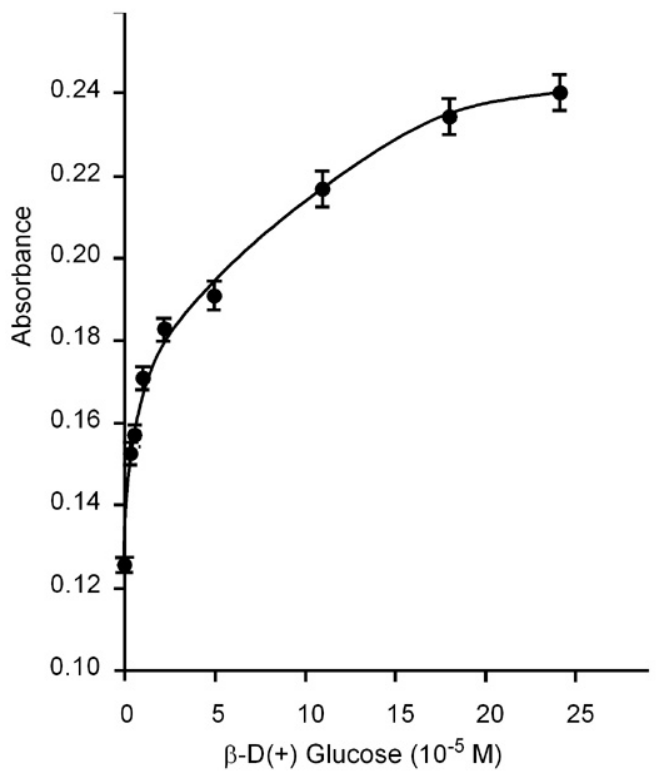

Figure 4S. Calibration curve corresponding to the absorbance at $\lambda=535 \mathrm{~nm}$ of the enhanced Au-NPs solutions upon interaction with different concentration of $\beta-\mathrm{D}(+)$ glucose. (Experimental conditions as in Figure 7). 